\title{
Orange Peels as a Sustainable Material for Treating Water Polluted with Antimony
}

\author{
Manar B. Hasan ${ }^{1 *}$, Israa M. Al-Tameemi ${ }^{1}$, Mohammed N. Abbas ${ }^{1}$ \\ 1 Department of Environmental Engineering, College of Engineering, Mustansiriyah University, \\ Bab Al Muadham, Baghdad 10047, Iraq \\ * Corresponding author's e-mail: manar@uomustansiriyah.edu.iq
}

\begin{abstract}
Water pollution has increased due to human activities; consequently, it is essential to treat both surface water and ground water so they are suitable to meet the needs of the population. This study will discuss water treatment intended to remove antimony. Antimony $(\mathrm{Sb})$ is classed as a high-priority toxic pollutant because of its adverse effects on ecosystems and human health. There are several methods for removing antimony from water, including adsorption, coagulation, ion exchange, and electrochemical treatment. This study focuses on the adsorption method as researchers have, in recent times, been seeking adsorbents that are environmentally friendly and cost-effective and that do not leave a residue. The study investigates the use of orange peels treated with acetic acid as an adsorbent to remove antimony ions from a simulated aqueous solution. The results revealed that $5 \mathrm{~g}$ of treated orange peels is $98.5 \%$ effective at treating water at a $\mathrm{pH}$ of 6 , for a contact time of 150 minutes, at a mixing speed of $450 \mathrm{rpm}$.
\end{abstract}

Keywords: Antimony treatment; Antimony adsorption; Polluted water; Orange peels; Low cost material

\section{INTRODUCTION}

The issue of water scarcity and the lack of clean water sources is becoming more and more pressing (Bolisetty et al., 2019). Increasing levels of contamination lead to low water quality and high remediation costs (Kumar et al., 2019). Human activates are one of the major causes of water contamination (Hasan and Al-Tameemi, 2018; Al-Tameemi et al., 2020; Murtadah et al., 2020). The release of contaminated wastewater or inadequately treated wastewater causes the degradation of natural ecosystems (Zhang et al., 2019; Al-Madhhachi et al., 2019; Hasan and Al-Madhhachi, 2018). Water may be contaminated with organic, pathogenic, and/or inorganic contaminates ( $\mathrm{He}$ and $\mathrm{Li}, 2020)$. Inorganic contaminants, including heavy metals, are characterized by their toxicity, non-biodegradability, and persistence in the environment (Xiao et al., 2019). Antimony $(\mathrm{Sb})$ is a heavy metal that exists naturally in soil, water, and sedimentary rocks. In water, it has four different valences $(+3,-3,+5$, and 0$)$, but the most prevalent valences are $\mathrm{Sb}(\mathrm{V})$ and $\mathrm{Sb}(\mathrm{III})$ (Long et al., 2019). $\mathrm{Sb}(\mathrm{V})$ is more abundant than $\mathrm{Sb}(\mathrm{III})$, which has less availability and higher toxicity (Deng et al., 2017). Toxicity, solubility, and other properties are based on $\mathrm{pH}$, as well as redox potential, with the result that the valence state $\mathrm{Sb}(\mathrm{V})$ exists in aerobic systems, such as in surface water, whereas $\mathrm{Sb}(\mathrm{III})$ is found in redox conditions, such as in groundwater (Deng et al., 2017).

Antimony has many industrial applications, for example, in the manufacture of lead alloys for the transportation industry. Other applications are the production of industrial materials, such as plastic, diodes, semi-conductors, as well as glass and ceramics (Mantha et al., 2018). The use of antimony in the industry is one of the reasons why its concentration in the natural environment has increased; in some cases, pollution is caused when it is discharged into the environment without being treated (Saeidnia et al., 2016). Antimony normally exists within a concentration range 
of $0.1-0.2 \mu \mathrm{g} /$ liter in untapped, unpolluted natural water sources. In the Yangtze River, the levels were found to be between $0.029-0.736 \mu \mathrm{g} / \mathrm{liter}$. This is the concentration in unpolluted samples. Anything exceeding this range would be considered indicative of abnormal interference (Long et al., 2019). Increasing concentrations of antimony in water, beyond its natural range, can be caused by drainage from acid mines or the wastewater of factory plants that use antimony. In the early 1990 s, for example, the concentration of antimony in groundwater located near abandoned antimony mines in Slovakia was up to $9,300 \mu \mathrm{g} / \mathrm{liter}$ (Huitzil-Tepanecatl et al., 2010). The allowable contaminant level of antimony in drinking water, set by the Environmental Protection Agency (EPA), is $6 \mu \mathrm{g} /$ liter (Xi et al., 2013). Exposure to a higher concentration than $6 \mu \mathrm{g} /$ liter negatively impacts the respiratory system, the skin, and the gastrointestinal system (Simeonidis et al., 2019). Many regions and countries have taken strict measures to control the concentration of antimony in aqueous solution. The Council of the European Union (CEC) and the United States Environmental Protection Agency (USEPA) have categorized antimony and its compounds as primary pollutants and have set the maximum allowable concentration of antimony in drinking water at 6 and $10 \mu \mathrm{g} /$ liter, respectively (CEC, 1980; USEPA, 1984). China has set the maximum concentration of antimony in drinking water at $5 \mu \mathrm{g} /$ liter, which is even stricter than international standards (Long et al., 2019).

Many methods have been employed to remove antimony from contaminated water, for example, adsorption, coagulation, and electrocoagulation (Simeonidis et al., 2019). However, such heavy-metal treatment methods are limited in their application as they are expensive and result in large quantities of sludge that must be disposed of. Currently, the adsorption of heavy metals is being extensively applied and has proven to be a simple, efficient, economic, eco-friendly, and reversible remedial technique. Numerous sorbent materials, such as activated carbon (Hasanzadeh et al., 2020), zeolite (Long et al., 2019), charcoal (Selintung et al., 2020), and silica (Long et al., 2019), have been used for the adsorption of heavy metal. Activated carbon is the most widely used sorbent due to its large surface area (Hsieh et al., 2019), but high preparation costs have led researchers to investigate low-cost, sustainable, and eco-friendly materials that can be used either as an adsorbent or as a raw material for the synthesis of a more economical type of activated carbon (Maddodi et al., 2020). The cost of the adsorption process can be further reduced by utilizing natural abandoned biomass. The use of bio-sorbents prepared from municipal solid waste, like aluminum foil waste (Ghulam et al., 2019) or agricultural by-products, is recognized as a sustainable, efficient, and economical remedial method. Agricultural and food waste contains large amounts of cellulose, fermentable sugar, and hemicellulose, which are beneficial in the adsorption of heavy metals. Several bio-sorbents obtained from agricultural waste have been used as efficient sorbent materials for the removal of heavy metals and serious pollutants from wastewater, such as sugarcane bagasse, almond shells (Brinza et al., 2020), Ulva Lactuca alga (Abbas et al., 2019a), watermelon rind (Abbas and Nussrat, 2020) and white eggshell (Abbas and Ibrahim, 2020), watermelon rind, lemon peel (Alalwan et al., 2019), rice husks (Abbas and Abbas, 2014; Abbas, 2015; Alalwan et al., 2018), and pomegranate peel (Abbas et al., 2019a). Such bio-sorbents have also been used to treat polluted soil (Abbas et al., 2019b) and Iraqi crude petroleum, which was treated using eggshells (Abbas and Alalwan, 2019; Abbas and Ibrahim, 2020; Ali et. al., 2020).

Around 71 million tons of oranges are produced annually around the world. Approximately $73 \%$ of these are consumed as fresh fruit, while $26 \%$ of the oranges are used for secondary products, primarily juice. Enormous quantities of agrifood waste are generated as a consequence of this large-scale production. In Iraq, the cultivation of oranges is one of the agro-economic activities that result in large quantities of bio-waste (orange peels). Therefore, orange peels are widely available as low-cost bio-waste. Making use of this waste for remediation would have both economic and environmental benefits. Widmer et al. (2010) indicated that a large portion of the global orange production results in waste that must be disposed of, creating environmental and economic burdens. Several researchers have utilized orange peels (OP) as economical, readily biodegradable sorbents due to their physio-chemical features. The OP consists of chlorophyll, lignin, pectin, cellulose, pigments, amid, carboxyl, and hydroxyl surface functional groups, and other lowmolecular-weight compounds. It is an abundant waste product that can be used for the adsorption of heavy metals (Pandiarajan et al., 2018) 
Several synthetic and modification methods have been used to prepare OP as adsorbents. Liang et al. (2010) prepared orange peel xanthate for the elimination of $\mathrm{Cu}^{2+}, \mathrm{Cd}^{2+}, \mathrm{Pb}^{2+}, \mathrm{Zn}^{2+}$, and $\mathrm{Ni}^{2+}$. The researchers reported that the adsorption isotherm accorded with the Langmuir model while the sorption kinetics accorded with pseudo-second-order. Gupta and Nayak (2012) magnetically modified OP for the elimination of $\mathrm{Cd}^{2+}$ from aqueous solution. Feng et al. (2009) modified OP for the adsorption of heavy metal through the interaction of methyl acrylate with cross-linking OP. The adsorption data were in keeping with the Langmuir equation. Pandiarajan et al. (2018) used potassium hydroxide $(\mathrm{KOH})$ to activate $\mathrm{OP}$ that was used for the adsorption of chlorophenoxyacetic acid herbicides from water. The addition of oxidizing agents can alter the surface properties of adsorbents. This indicates the feasibility of OP for the adsorption of heavy metals from aqueous solutions. Therefore, the objectives of this study were to investigate the feasibility of raw OP (ROP) and acetic acid-treated OP (TOP) in the adsorption of antimony from synthetic wastewater using a batch-mode adsorption unit and to identify the optimum remediation conditions.

\section{METHODS AND MATERIALS}

\section{Adsorbents}

Orange peels (OP) were collected from household waste and the waste of a selection of fast-food stores in Baghdad, Iraq. The OP were washed with tap water and then with ionic water to remove impurities. The OP were cut into small pieces, the length of which ranged between 0.5 to $2 \mathrm{~cm}$. The peels were dried in two stages. They were left in the open air, exposed to the sun, for seven days, and then they were dried in the oven at a temperature of $40^{\circ} \mathrm{C}$ for 1 hour. The dried peels were divided into two halves. One half (representing the ROP) of the peels were kept in opaque, sealed glass flasks until they were needed. The other half of the peels were treated with an absolute solution of acetic acid (glacial acetic acid) obtained from Sigma-Aldrich by soaking them in the acid solution (at a rate of $5 \mathrm{ml}$ of acid/g of orange peel) for 24 hours at room temperature. The peels were then removed from the solution and exposed to air in a dry place, away from sunlight, until they dried. These treated peels represent the
TOP. The TOP were stored in the same manner as the ROP until needed.

Adsorption of antimony ions was conducted using the ROP and TOP. Synthetic wastewater was used during the experiment to avoid the interference of any compounds and elements likely to be present in real wastewater. The wastewater was prepared by dissolving $2.2 \mathrm{~g}$ of potassium hexahydroxoantimonate (V) $\mathrm{KO}_{6} \mathrm{Sb}$ salt, manufactured by Sigma-Aldrich, in 1 liter of distilled water to obtain a solution with a concentration of $1000 \mathrm{ppm}$ pentavalent antimony. All aqueous solutions used in the adsorption experiments were prepared by diluting the specified volume of the stock solution to the required concentration.

\section{Adsorption of Antimony}

To achieve the objectives of this study, the effects of several operating conditions with different ranges in the adsorption process were examined to determine the maximum removal rate of pentavalent antimony ions from aqueous solutions. The conditions studied included the acidity function effect of the aqueous solution $(\mathrm{pH})$, the initial concentration of antimony, the dose of the adsorbent material (ROP and TOP), the agitation speed, and the contact time, within ranges from 1 to 9,1 to $100 \mathrm{ppm}, 0.1$ to $5 \mathrm{~g}, 100$ to $500 \mathrm{rpm}$, and 10 to 180 minutes, respectively. All experiments were conducted by mixing a specific dose of absorbent material (the ROP or TOP dose) with $100 \mathrm{ml}$ of antimony solution at a specific concentration in a $150 \mathrm{~m}$ conical flask in a batch system involving a water bath shaker. The $\mathrm{pH}$ of the solution was adjusted using a $0.1 \mathrm{~N}$ solution of hydrochloric acid $(\mathrm{HCl})$ and sodium hydroxide $(\mathrm{NaOH})$ obtained from Sigma-Aldrich. After stabilizing the temperature and operating the system at the required speed, samples were extracted and filtered using filter paper. The remaining concentration of antimony was determined using a Shimadzu (Japan) atomic absorption spectrometer. The correction curve at the max wavelength of $217.6 \mathrm{~nm}$ is shown in Figure 1.

\section{Isotherm investigation}

The equilibrium studies giving the capacity of both adsorbent and adsorbate are depicted by adsorption isotherms, which generally represent the rate between the quantity adsorbed and the quantity remaining in the aqueous solution at equilibrium, at a constant temperature, $\mathrm{pH} 6$ 


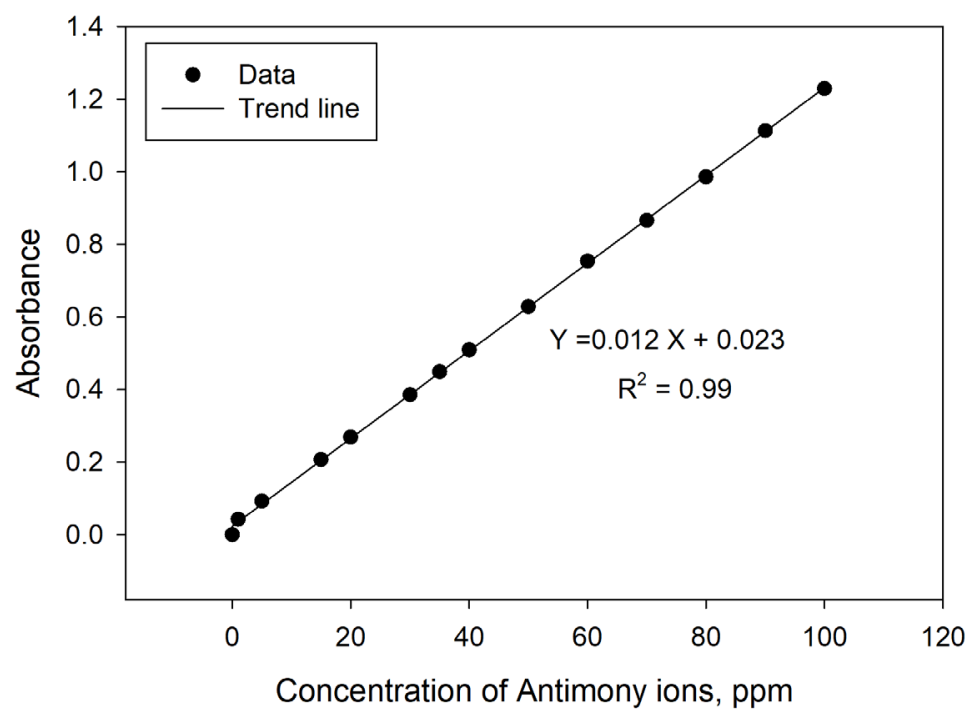

Figure 1. The calibration curve of Antimony ions.

and 5, $400 \mathrm{rpm}$ and $450 \mathrm{rpm}$ agitation speed, for 150 minutes to ROP and TOP, respectively. Freundlich and Langmuir isotherms are the most established and best-known isotherms describing the adsorption equation.

The Langmuir equation is employed to evaluate the biggest adsorption capability, which is identical to complete monolayer coverage on the surface of the adsorbent, and is formulated as follows (Fan et al., 2019):

$$
q_{e}=\frac{q_{\max } K_{L} C_{e}}{1+K_{L} C_{e}}
$$

After rearrangement, the linear form of the above formula can be expressed as follows:

$$
\frac{C_{e}}{q_{e}}=\frac{1}{q_{\max } K_{L}}+\frac{C_{e}}{q_{\max }}
$$

By plotting $C_{e} / q_{e}$ against $C_{e}$, the experimental data is fitted into the above formula for linearization. Both constants $K_{L}$ and $q_{\max }$ can be estimated from the intercept and slope, respectively.

where: $q_{e}$ is the sorbed metal ions on the biomass in $\mathrm{mg} / \mathrm{g}$,

$q_{\max }$ is the maximum sorption capacity for monolayer coverage in $\mathrm{mg} / \mathrm{g}$,

$K_{L}$ is the constant related to the affinity of the binding site in $1 / \mathrm{mg}$,

$C_{e}$ is the concentration of metal ions in the solution at equilibrium in $\mathrm{mg} / \mathrm{l}$. The Langmuir isotherm is most frequently used to describe the adsorption isotherm, which is limited by the assumptions of uniform energies of adsorption on the surface of the adsorbent.
To determine the adsorption intensity of the sorbent to the adsorbate, the Freundlich model has been used as an empirical equation (Fan et al., 2019):

$$
q_{e}=K_{F} C_{e}^{\frac{1}{n}}
$$

The magnitude of $n$ specifies the affinity of the adsorbate towards the adsorbent. The above equation is conveniently expressed in linear form as follows:

$$
\ln q_{e}=\ln K_{F}+\frac{1}{n} \ln C_{e}
$$

By plotting $\ln C_{e}$ against $\ln q_{e}$, the experimental data can be fitted into the above formula for linearization. Both constants $1 / n$ and $\ln K_{F}$ can be estimated from the intercept and slope respectively. Where $K_{F}$ is the constant indicative of the relative adsorption capacity of the adsorbent in $\mathrm{mg} / \mathrm{g}, n$ is the constant indicative of the intensity of the adsorption.

The study of adsorption dynamics defines the contaminate uptake rate and evidently. This rate controls the residence time of adsorbate uptake at the solid-solution interface. The kinetics of $\mathrm{Sb}^{+3}$ adsorption on the orange peels was examined using pseudo-first-order and pseudo-second-order kinetic models (Fan et al., 2014). The pseudofirst-order kinetic model was expressed by the following equation (Fan et al., 2014):

$$
\ln \left(q_{e}-q_{t}\right)=\ln q_{e}-k_{1} t
$$

The values of $k_{1}$ and $q_{e}$ were calculated using the slope and intercept values of the straight line created by plotting $\ln \left(q_{e}-q_{t}\right)$ versus $t$. The 
sorption data were also analyzed in terms of the pseudo-second-order model given by the following equation (Fan et al. 2014):

$$
\frac{t}{q_{t}}=\frac{1}{K_{2} q_{e}^{2}}+\frac{1}{q_{e}} t
$$

By substituting the initial adsorption rate of $h=K_{2} q_{e}^{2}$ in Equation 6, Equation 7 is expressed as:

$$
\frac{t}{q_{t}}=\frac{1}{h}+\frac{1}{q_{e}} t
$$

Plotting $t / q_{t}$ against $t$ should result in a straight line. The pseudo-second-order rate constant $K_{2}$ and equilibrium adsorption capability $q_{e}$ were determined using the values of the intercept and the slope, respectively. Where $q_{e}$ is the amount of metal sorbed at equilibrium in $\mathrm{mg} / \mathrm{g}, q_{t}$ is the amount of metal sorbed at time $t \mathrm{in} \mathrm{mg} / \mathrm{g}, K_{l}$ is the equilibrium rate constant of pseudo-first sorption in $1 / \mathrm{min}$, and $K_{2}$ is the pseudo-second-order rate constant in $\mathrm{g} / \mathrm{mg}$. hr.

\section{RESULTS AND DISCUSSION}

Experiments were carried out in order to determine the best conditions for the removal of antimony $\mathrm{Sb}(\mathrm{V})$. Results revealed that the initial concentration of the contaminant had a significant effect on the adsorption capacity of both raw orange peels (ROP) and treated orange peels (TOP) as adsorbents of $\mathrm{Sb}(\mathrm{V})$ ions within a pollutant concentration range of 1 to $100 \mathrm{ppm}$ when the rest of the operational factors were fixed at optimum values. In general, the results obtained showed that there is an inverse relationship between the efficiency of the adsorption process and the initial concentration: the higher initial concentration value, the lower the processing efficiency, as shown in Figure 2. When the initial concentration of $\mathrm{Sb}(\mathrm{V})$ was $1 \mathrm{ppm}$, the adsorption rate was at its highest of $84 \%$ and $100 \%$ for both the ROP and the TOP, respectively. At an increased initial concentration of $100 \mathrm{ppm}$, the adsorption rate was at its lowest of $26 \%$ and $46 \%$ for ROP and TOP, respectively.

This result can be attributed to the fact that the amount of the adsorbent material used (ROP or TOP) has a specific surface area; consequently, it has a specific number of effective sites for the adsorption of the contaminant ions, which determines the specific number of $\mathrm{Sb}(\mathrm{V})$ ions that can be removed. When the concentration of the contaminant is low, the amount of $\mathrm{Sb}(\mathrm{V})$ is low with a constant volume and the ROP or TOP will adsorb a high percentage of $\mathrm{Sb}(\mathrm{V})$ ions and only a small amount of $\mathrm{Sb}(\mathrm{V})$ will remain in the solution. On the other hand, a high concentration of the contaminant means that there is a high amount of $\mathrm{Sb}(\mathrm{V})$ ions, in which case the number of nonadsorbed ions will be greater since the number of ions adsorbed on the surface of the adsorbent substance is constant due to the amount of the adsorbent substance being constant. For this reason, adsorption efficiency decreases due to the high diffusion concentration of the solution. A oneway analysis of variance (ANOVA) technique using a normality test (Shapiro-Wilk) reported the mean values of removable antimony as $86.80 \%$

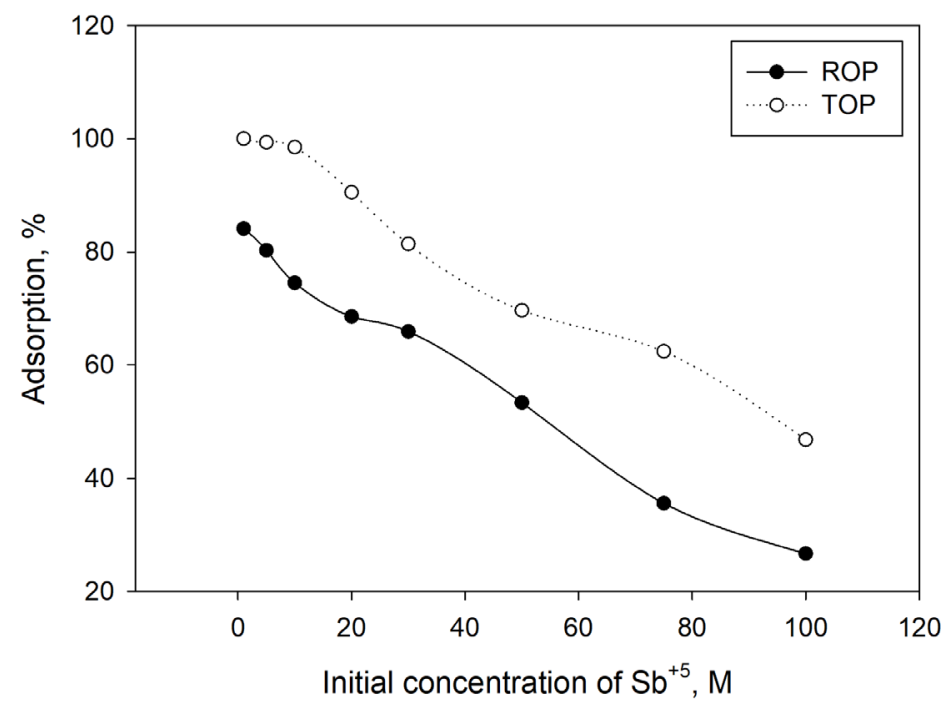

Figure 2. Effect of initial concentration on the adsorption capacities of ROP and TOP in relation to $\mathrm{Sb}+5$ ions. 
and $91.85 \%$ for the ROP and TOP, respectively. The standard deviations of removable antimony were $20.68 \%$ and $12.02 \%$ for the ROP and TOP, respectively. Multiple comparisons using Tukey's test indicated that there was a statistically significant difference among removable percentages of antimony at different concentrations using ROP and TOP with a P-value of less than 0.002 .

The second parameter in the evaluation of the effectiveness of the adsorbent in pollutant removal was the dose of the adsorbent. Experiments were carried out using between 0.1 to $5 \mathrm{~g}$ of adsorbent, with rest of the operational variables at fixed optimum conditions. The results obtained are represented in Figure 3, which shows that the adsorbent's efficiency removing $\mathrm{Sb}(\mathrm{V})$ ions is in direct relation to the dose of adsorbent (ROP or TOP). At the lowest dose of peels of $1 \mathrm{~g}$, the efficiency of the ROP and TOP is $75 \%$ and $86 \%$, respectively, while it reaches its highest efficiency of $96 \%$ and $100 \%$ at a dose of $5 \mathrm{~g}$ for both types of orange peels (ROP and TOP). Based on this result, the optimum amount of sorbent was determined to be $5 \mathrm{~g}$. In other words, an increase in the amount of the adsorbent led to an increase in adsorption capacity. This is due to the fact that the surface area is directly proportional to the dose of peels used. A smaller amount of peels means a smaller surface area, with fewer effective sites, as a result of which the amount of adsorbed $\mathrm{Sb}(\mathrm{V})$ ions is low and the removal efficiency remains at the lowest levels. Increasing the amount of adsorbent material leads to a greater number of effective sites and the adsorption of a greater amount of $\mathrm{Sb}(\mathrm{V})$ ions; thus, the percentage of removal increases. The typical dosage for adsorbent was selected as $5 \mathrm{~g}$ for both ROP and TOP.

Figure 4 illustrates the effect of contact time on the removal of $\mathrm{Sb}(\mathrm{V})$ ions. The contact time ranged from 10 to 180 minutes, with a fixed initial $\mathrm{Sb}(\mathrm{V})$ concentration of $50 \mathrm{ppm}$ for ROP and $75 \mathrm{ppm}$ for TOP and a $5 \mathrm{~g}$ dose of the sorbent. When the contact time increased, there was a corresponding increase in pollutant elimination. After the first 60 minutes of contact time, the percentage of $\mathrm{Sb}(\mathrm{V})$ removal was high at $49 \%$ to $87 \%$ for ROP and at $65 \%$ to $93 \%$ for TOP. The average rate of adsorption became slower during the second 60 minutes of contact time. The adsorption rates were $87 \%$ to $94 \%$ for ROP and $93 \%$ to $98 \%$ for TOP. During the third period of 60 minutes, the capacity of adsorption was slowest and semi-constant. The adsorption rates were $94 \%$ to $96 \%$ for ROP and $98 \%$ to $100 \%$ for TOP. The reason for the increased removal of $\mathrm{Sb}(\mathrm{V})$ ions in the first contact time period of 60 minutes and the almost constant average in the third period, once equilibrium had been achieved, was the result of the vacant adsorbent sites being occupied by a high concentration of solute at the beginning of the contact time before being saturated as the contact time increased; thus, an optimum contact time of 150 minutes was selected for both ROP and TOP.

Acidity is one of the most important factors, so the effect of $\mathrm{pH}$ change was studied within a range of 1 to 9 , in order to include the acidic, neutral, and alkaline states, with other operational

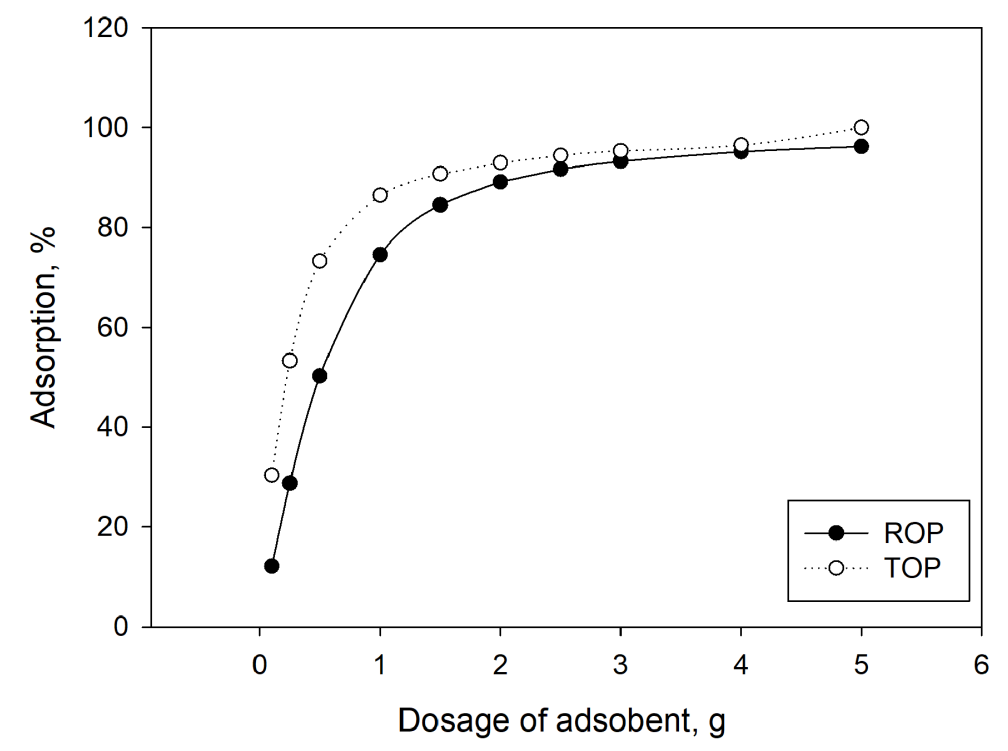

Figure 3. Effect of adsorbent dosage on the adsorption capacities of ROP and TOP for $\mathrm{Sb}(+5)$ ions. 


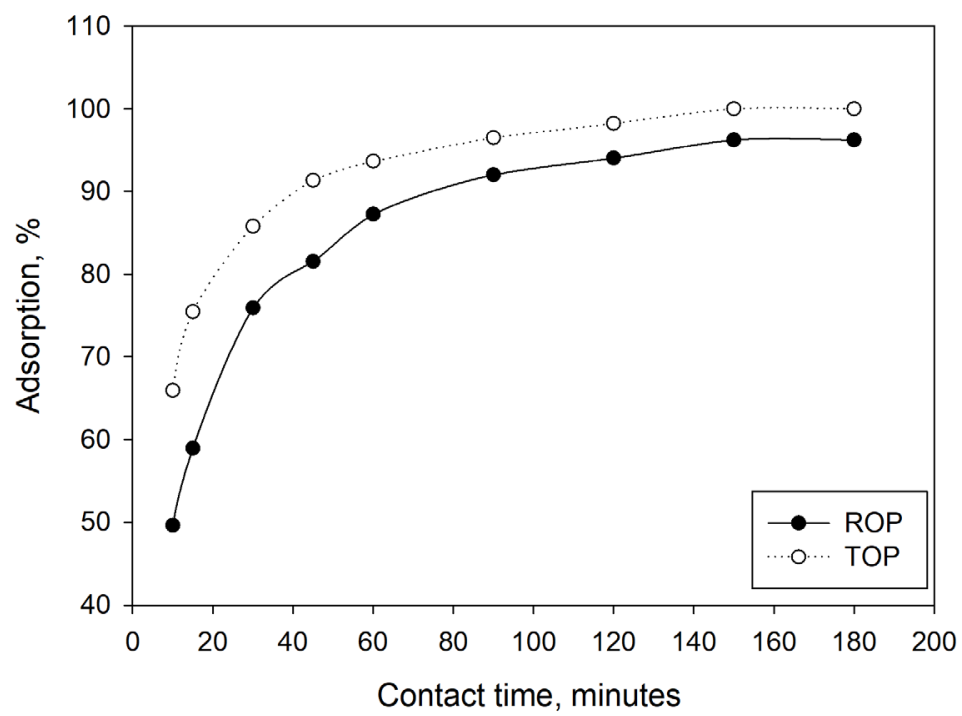

Figure 4. Effect of adsorption time on the adsorption capacities of ROP and TOP for $\mathrm{Sb}+5$ ions.

variables stabilized at optimal values. The results of the experiments indicated that the efficiency of the adsorption process was in a non-fixed and variable relationship with the acidic function of the solution. There was a direct relationship within the $\mathrm{pH}$ range 1 to 6 , whereas there was an inverse relationship within the $\mathrm{pH}$ range of 6 to 9. When the concentration of hydrogen ions increased, the $\mathrm{pH}$ value of the solution decreased as the relationship between them is logarithmic. At lower values of the acidic function, the chance of adsorption of positive antimony ions on the surface of the peels decreases due to increased competition between them and the high-concentration of positive protons. In addition, the surface of the adsorbent material has a positive charge that repulses the positive antimony ions, which increases in number as the value of the acidic function of the solution decreases. Thus, the adsorption efficiency decreases as the $\mathrm{pH}$ is decreased. At $\mathrm{pH}$ 6, the acid effect is greatly reduced, which results in the maximum adsorption efficiency of $73 \%$ and $99 \%$ for both ROP and TOP, respectively.

Above $\mathrm{pH}$ 6, the removal efficiency increases sharply until it reaches the highest level. This may be due to an increase in the concentration of negative hydroxide ions, which could lead to the deposition of $\mathrm{Sb}(\mathrm{V})$ ions in the form of salts at the bottom of the beaker, resulting in ionization and reduced movement in the solution and thereby reducing diffusion and ultimately increasing the removal efficiency through sedimentation and not adsorption. Therefore, the optimum acid value is 6, as shown in Figure 5. The best $\mathrm{pH}$ to remove the maximum amount of $\mathrm{Sb}(\mathrm{V})$ ions was 6 in the case of ROP and 5 in the case of TOP.

Figure 6 shows the effect of the agitation speed on the removal of $\mathrm{Sb}(\mathrm{V})$ ions from aqueous solutions, with the rest of the factors at optimum values. It is clear from the figure that the two variables are in a direct relationship whereby the removal efficiency increases as the mixing speed increases until it reaches its maximum value, which is $74.52 \%$ and $98.52 \%$ at mixing speeds of 400 and $450 \mathrm{rpm}$ for ROP and TOP, respectively. Above this speed, the removal efficiency becomes fixed. This is the result of diffusivity: Increasing the mixing velocity improves the diffusion behavior of the $\mathrm{Sb}(\mathrm{V})$ ions in the solution and so the chance of these ions being adsorbed on the surface of the orange peel increases by the effective functional groups. Increasing the mixing velocity of the solution also breaks the boundary layers surrounding the adsorbent particles, which facilitates the movement of $\mathrm{Sb}(\mathrm{V})$ ions to the effective sites of adsorption. The removal efficiency continues to rise until the mixing speed reaches 400 and $450 \mathrm{rpm}$. After exceeding these speeds, there is no change in the removal efficiency as the adsorbent particles have been saturated with $\mathrm{Sb}(\mathrm{V})$ ions and therefore any increase in the mixing speed does not affect efficiency.

During the batch adsorption experiment, the concentration of antimony was evaluated over the course of contact time of 150 minutes. This was done by introducing $5 \mathrm{mg}$ of ROP into $100 \mathrm{ml}$ of the sample at $\mathrm{pH} 6$ and an agitation speed of $400 \mathrm{rpm}$. Similarly, $5 \mathrm{mg}$ of TOP was placed into 


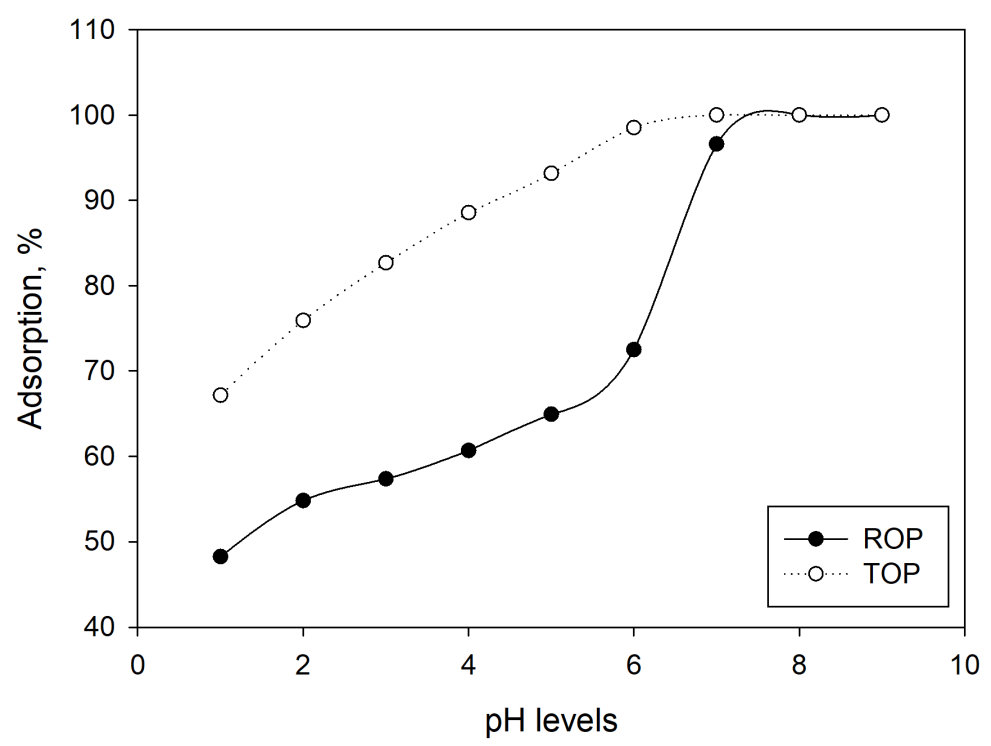

Figure 5. Effect of $\mathrm{pH}$ levels on the adsorption capacities of ROP and TOP for $\mathrm{Sb}+5$ ions.

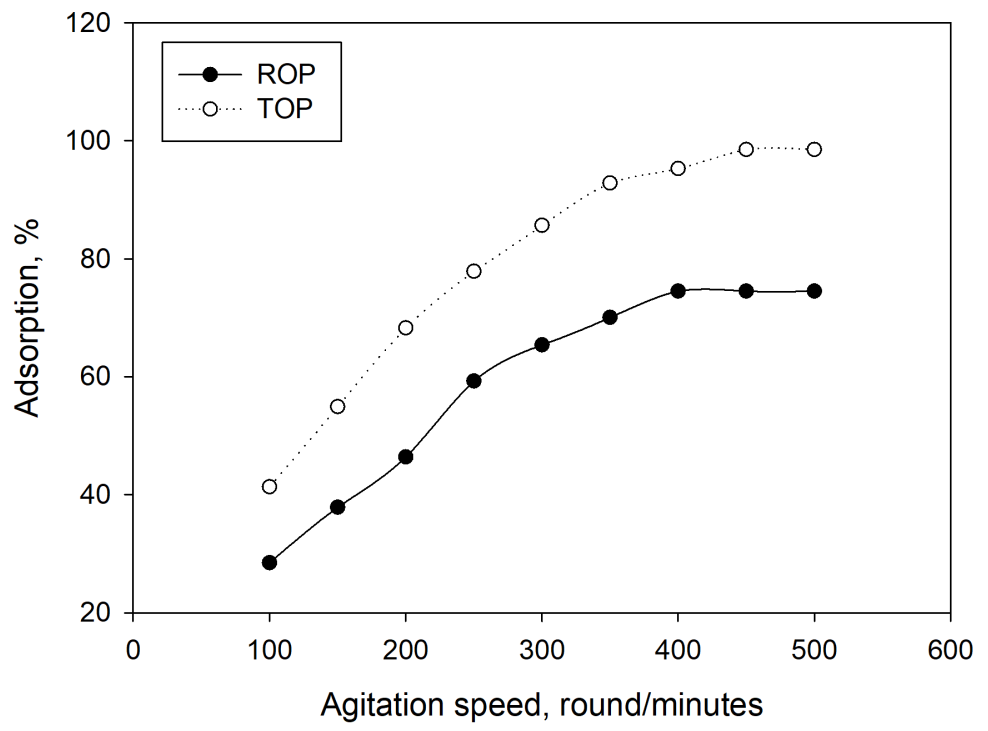

Figure 6. Effect of agitation speed on the adsorption capacities of ROP and TOP for $\mathrm{Sb}+5$ ions.

$100 \mathrm{ml}$ of the sample at $\mathrm{pH} 5$ and an agitation speed of $450 \mathrm{rpm}$. The results of the experiments demonstrated that orange peels treated with acetic acid (TOP) were more effective than raw orange peels (ROP) in the adsorption of $\mathrm{Sb}(\mathrm{V})$ as they removed $93.16 \%$ of the pollutant, in contrast to approximately of $72.5 \%$ removed by the ROP. Therefore, acidic conditions are the best environment for $\mathrm{Sb}(\mathrm{V})$ adsorption. To improve the rate of $\mathrm{Sb}(\mathrm{V})$ uptake, orange peels were treated with acetic acid as a catalyst. The reason for the increase in the removal of $\mathrm{Sb}(\mathrm{V})$ when using TOP was the reduction in the $\mathrm{pH}$ of the solution. That is, when the water $\mathrm{pH}$ decreased, the number of $\mathrm{H}^{+1}$ ions increased, which resulted in more active sites with a greater number of positive surface sites. Thus, an increase in $\mathrm{Sb}(\mathrm{V})$ uptake was achieved.

The data from the experiments were employed in the two isotherms in Figures 7 and 8. The results showed that the adsorption of $\mathrm{Sb}(\mathrm{V})$ ions by a treated orange peel is in keeping with the Langmuir isotherm model because this model provides a greater correlation coefficient $\left(\mathrm{R}^{2}=1.00\right)$ value than the Freundlich isotherm model $\left(\mathrm{R}^{2}=0.88\right)$, consequently confirming the assumption that the adsorbate molecules could be adsorbed through monolayer coverage on the surface of the adsorbent. Results showed that adsorption was in keeping with the Langmuir model. These results are based on the assumption that maximum 


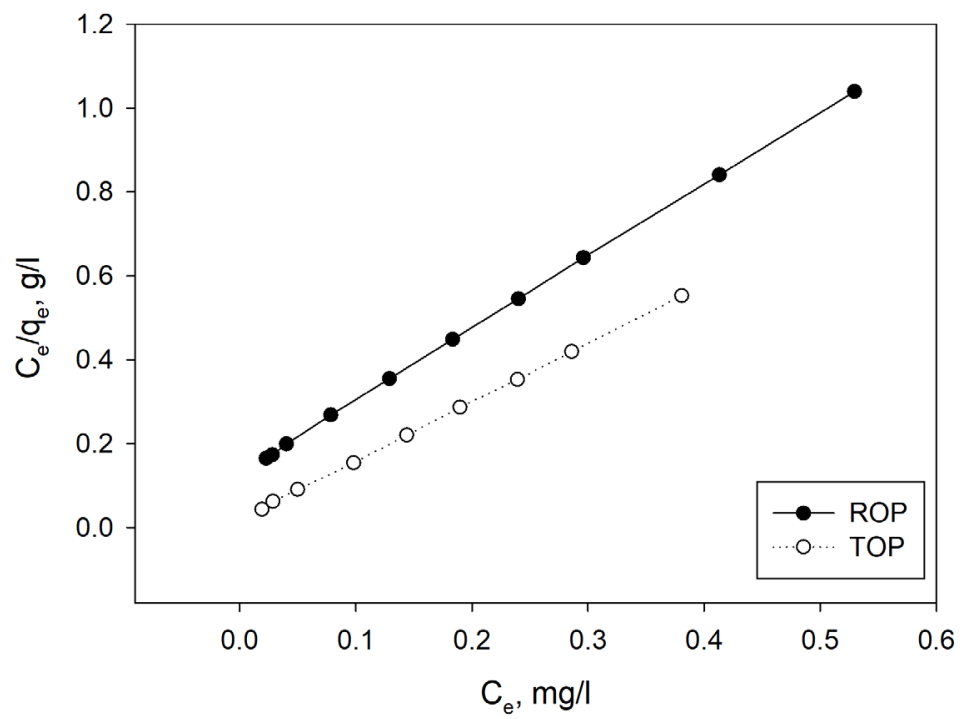

Figure 7. Langmuir isotherms of the adsorption process of ROP and $\mathrm{TOP}$ for $\mathrm{Sb}+5$ ions.

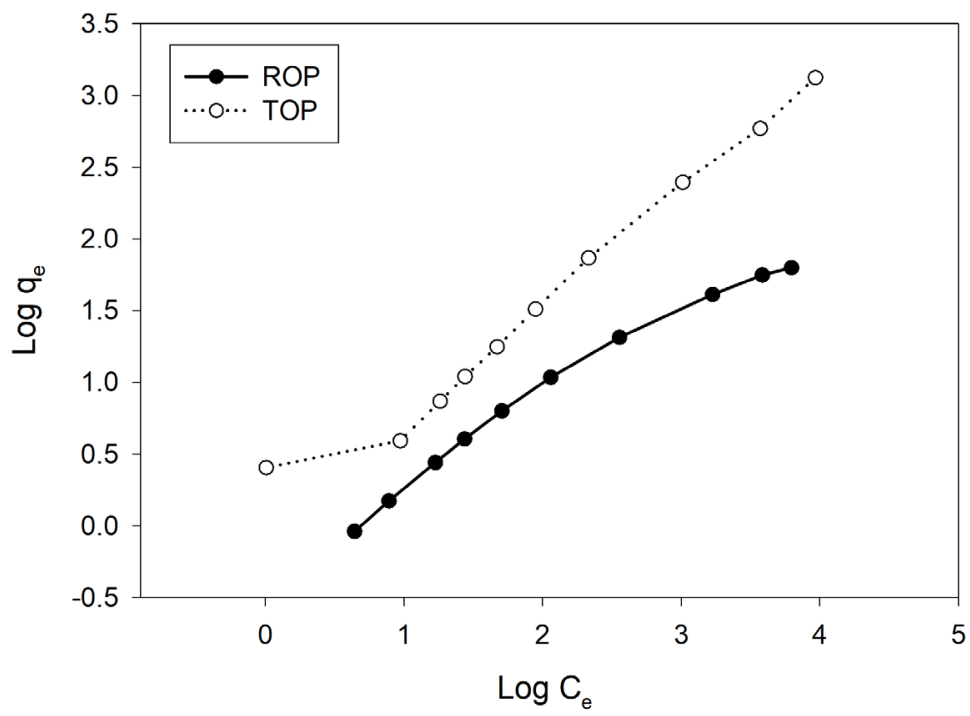

Figure 8. Freundlich isotherms of the adsorption process of $\mathrm{ROP}$ and $\mathrm{TOP}$ for $\mathrm{Sb}+5$ ions.

adsorption corresponds to a saturated monolayer of solute molecules on the surface of the adsorbent, that the energy of adsorption is constant, and that there is no transmigration of adsorbate on the plane of the surface.

\section{CONCLUSIONS}

Our experiments verified that orange peels can be used in order to reduce the level of antimony in the water when treating polluted water in accordance with environmental regulations. Orange peels treated with acetic acid (TOP) were more efficient than raw orange peels (ROP) in the removal of $\mathrm{Sb}(\mathrm{V})$. With a contact time of 150 minutes, a sorbent dosage of $5 \mathrm{mg}$, and $\mathrm{pH} 6$, the adsorption capacities were elevated from $72.5 \%$ for the case of ROP to $98.5 \%$ for the case of TOP. The results show that the uptake of $\mathrm{Sb}(\mathrm{V})$ is influenced by a range of parameters, such as acidity function, the dose of orange peels, mixing speed, the initial concentration of $\mathrm{Sb}(\mathrm{V})$, as well as the contact time. For higher adsorption of $\mathrm{Sb}(\mathrm{V})$ from the polluted solution, an adsorbent dose of $5 \mathrm{~g}$ was favorable. The uptake of $\mathrm{Sb}(\mathrm{V})$ from the solution was increased by increasing the contact time. The ideal contact time was deemed to be 150 minutes. The maximum $\mathrm{Sb}(\mathrm{V})$ removal from solution was approximately $93 \%$ at $\mathrm{pH} 5$, a mixing speed of $450 \mathrm{rpm}$, using $5 \mathrm{~g}$ of TOP for a contact time of 150 minutes. The experimental data were fitted 
by the Langmuir isotherm model. Orange peels are therefore a cost-effective and eco-friendly adsorbent for the removal of antimony from water.

\section{Acknowledgements}

The authors acknowledge the Faculty of Engineering, Mustansiriyah University (http://www. uomustansiriyah.edu.iq) for their valuable help in fixing and sustaining the apparatus utilized in this research.

\section{REFERENCES}

1. Abbas M. N. 2015. Phosphorus removal from wastewater using rice husk and subsequent utilization of the waste residue. Desalination and Water Treatment, 55(4), 970-977.

2. Abbas M. N., Abbas F. S. 2014. Application of Rice Husk to Remove Humic Acid from Aqueous Solutions and Profiting from Waste Leftover. WSEAS Transactions on Biology and Biomedicine, 11(9), 62-69.

3. Abbas M. N., Alalwan H. A. 2019. Catalytic Oxidative and Adsorptive Desulfurization of Heavy Naphtha Fraction. Korean Journal of Chemical Engineering, 12(2), 283-288. DOI: 10.9713/ kcer.2019.57.2.283.

4. Abbas M. N., Al-Hermizy S. M., Abudi Z. N., Ibrahim T. A. 2019a. Phenol Biosorption from Polluted Aqueous Solutions by Ulva lactuca Alga using Batch Mode Unit. Journal of Ecological Engineering, 20(6), 225-235.

5. Abbas M. N., Al-Madhhachi A. T., Esmael S. A. 2019b. Quantifying soil erodibility parameters due to wastewater chemicals. Int. J. Hydrology Science and Technology, 9(5), 550-568.

6. Abbas M. N., Ibrahim S. A. 2020. Catalytic and thermal desulfurization of light naphtha fraction. Journal of King Saud University-Engineering Sciences, 32(4), 229-235.

7. Abbas M. N., Nussrat T. H. 2020. Statistical Analysis of Experimental Data for Adsorption Process of Cadmium by Watermelon Rinds in Continuous Packed Bed Column. International Journal of Innovation, Creativity and Change, 13(3), 124-138.

8. Alalwan H. A., Abbas M. N., Abudi Z. N., Alminshid A. H. 2018. Adsorption of thallium ion $(\mathrm{Tl}+3)$ from aqueous solutions by rice husk in a fixed-bed column: Experiment and prediction of breakthrough curves. Environmental Technology and Innovation, $12,1-13$.

9. Ali G. A. A., Ibrahim S. A., Abbas M. N. 2020. Catalytic Adsorptive of Nickel Metal from Iraqi Crude
Oil using non-Conventional Catalysts. Innovative Infrastructure Solutions, 6(7), 9.

10. Al-Madhhachi A. T., Mutter G. M., Hasan M. B. 2019. Predicting Mechanistic Detachment Model due to Lead-Contaminated Soil Treated with Iraqi Stabilizers. KSCE Journal of Civil Engineering, 23(7), 2898-2907.

11. Al-Tameemi I. M., Hasan M. B., Al-Mussawy H. A., Al-Madhhachi A. T. 2020. Groundwater Quality Assessment Using Water Quality Index Technique: A Case Study of Kirkuk Governorate, Iraq. In IOP Conference Series: Materials Science and Engineering, 881(1), 012185.

12. Bolisetty S., Peydayesh M., Mezzenga R. 2019. Sustainable Technologies for Water Purification from Heavy Metals: Review and Analysis, Chemical Society Reviews, 48(2), 463-87.

13. Brinza L., Geraki K., Cojocaru C., Holdt S. L., Neamtu M. 2020. Baltic Fucus Vesiculosus as Potential Bio-Sorbent for Zn Removal: Mechanism Insight, Chemosphere, 238, 124652.

14. Deng R. J., Jin C. S., Ren B. Z., Hou B. L., Hursthouse A. S. 2017. The Potential for the Treatment of Antimony-Containing Wastewater by Iron-Based Adsorbents, Water (Switzerland), 9 (10).

15. Fan H., Sun Y., Tang Q., Li W., Sun T. 2014. Selective Adsorption of Antimony (III) from Aqueous Solution by Ion-Imprinted Organic-Inorganic Hybrid Sorbent: Kinetics, Isotherms and Thermodynamics. Journal of the Taiwan Institute of Chemical Engineers, 45(5), 2640-2648.

16. Fan Y., Zheng C., Huo A., Wang Q., Shen Z., Xue Z., He C. 2019. Ecotoxicology and Environmental Safety Investigating the Binding Properties between Antimony (V) and Dissolved Organic Matter (DOM) under Different $\mathrm{pH}$ Conditions during the Soil Sorption Process Using Fluorescence and FTIR Spectroscopy. Ecotoxicology and Environmental Safety, 181, 34-42.

17. Feng N., Guo X., Liang S. 2009. Adsorption study of copper (II) by chemically modified orange peel. Journal of Hazardous Materials, 164(2-3), 1286-1292.

18. Ghulam N. A., Abbas M. N., Sachit D. E. 201. Preparation of synthetic alumina from aluminium foil waste and investigation of its performance in the removal of RG-19 dye from its aqueous solution. Indian Chemical Engineer, 62(3), 301-313.

19. Gupta V. K., Nayak A. 2012. Cadmium removal and recovery from aqueous solutions by novel adsorbents prepared from orange peel and $\mathrm{Fe} 2 \mathrm{O} 3$ nanoparticles. Chemical Engineering Journal, 180(15), 81-90.

20. Hasan M. B., Al-Tameemi, I. M. 2018. Carbofuran Elimination from Synthetic Wastewater Employing AOPS. International Journal of Civil Engineering and Technology, 9(10), 491-99. 
21. Hasan M. B., Al-Madhhachi A. T. 2018. The influence of crude oil on mechanistic detachment rate parameters. Geosciences, 8(9), 332.

22. Hasanzadeh M., Simchi A., Far H. S. 2020. Nanoporous Composites of Activated Carbon-Metal Organic Frameworks for Organic Dye Adsorption: Synthesis, Adsorption Mechanism and Kinetics Studies. Journal of Industrial and Engineering Chemistry, $81,405-14$

23. He X., Li P. 2020. Surface Water Pollution in the Middle Chinese Loess Plateau with Special Focus on Hexavalent Chromium (Cr 6+): Occurrence, Sources and Health Risks. Exposure and Health, $1-17$.

24. Hsieh L. C., Ou H., Huang C. 2019. Adsorption of $\mathrm{Cu}$ (II) in Aqueous Solution Using MicrowaveAssisted Titanate Nanotubes. Applied Nanoscience, 9 (4), 505-14.

25. Huitzil-Tepanecatl A., Cocoletzi G. H., Takeuchi N. 2010. Ab Initio Study of the Adsorption of Antimony and Arsenic on the $\mathrm{Si}(110)$ Surface. Thin Solid Films, 519 (1), 265-69.

26. Kumar V., Parihar R. D., Sharma A., Bakshi P., Sidhu G. S., Bali A. S., Karaouzas I., Bhardwaj R., Thukral A. K., Gyasi-Agyei Y. 2019. Global Evaluation of Heavy Metal Content in Surface Water Bodies: A Meta-Analysis Using Heavy Metal Pollution Indices and Multivariate Statistical Analyses. Chemosphere, 124364.

27. Liang S., Guo X., Feng N., Tian Q. 2010. Effective removal of heavy metals from aqueous solutions by orange peel xanthate. Transactions of Nonferrous Metals Society of China, 20(1), 187-191.

28. Long X., Wang X., Guo X., He M. 2019. A Review of Removal Technology for Antimony in Aqueous Solution. Journal of Environmental Sciences, 90, $1-16$.

29. Maddodi S. A., Alalwan H. A., Alminshid A. H., Abbas M. N. 2020. Isotherm and computational fluid dynamics analysis of nickel ion adsorption from aqueous solution using activated carbon. South African Journal of Chemical Engineering, 32, 5-12.

30. Mantha Z., Tzollas N., Stylianou S., Katsoyiannis I., Zouboulis M., Anastasios M. 2018. Removal of Antimony Species, $\mathrm{Sb}(\mathrm{III}) / \mathrm{Sb}(\mathrm{V})$, from Water by Using Iron Coagulants. Water (Switzerland), 10(10), 1328.
31. Murtadah I., Al-Sharify Z. T., Hasan M. B. 2020. Atmospheric Concentration Saturated and Aromatic Hydrocarbons Around Dura Refinery. In IOP Conference Series: Materials Science and Engineering, 870(1), 012033.

32. Pandiarajan A., Kamaraj R., Vasudevan S., Vasudevan S. 2018. OPAC (orange peel activated carbon) derived from waste orange peel for the adsorption of chlorophenoxyacetic acid herbicides from water: adsorption isotherm, kinetic modelling and thermodynamic studies. Bioresource Technology, 261, 329-341.

33. Saeidnia S., Asadollahfardi G., Darban A. K., Mohseni M. 2016. Simulation of Antimony Adsorption on Nano-Zero Valent Iron and Kaolinite and Analyzing the Influencing Parameters. Water Science and Technology, 73 (10), 2493-2500.

34. Selintung, M., Mangarengi N. A. P., Zubair A. 2020. The Reduction of Heavy Metals Cd and Cr Levels in Wastewater Using Bagasse Charcoal as an Adsorbent. IOP Conference Series: Earth and Environmental Science, 419: 12171.

35. Simeonidis K., Martinez-Boubeta C., Zamora-Pérez P., Rivera-Gil P., Kaprara E., Kokkinos E., Mitrakas M. 2019. Implementing Nanoparticles for Competitive Drinking Water Purification. Environmental Chemistry Letters, 17(2), 705-19.

36. Widmer W., Zhou W., Grohmann K. 2010. Pretreatment effects on orange processing waste for making ethanol by simultaneous saccharification and fermentation. Bioresource Technology, 101, 5242-5249.

37. Xi J., He M., Wang P. 2013. Adsorption of Antimony on Sediments from Typical Water Systems in China: A Comparison of Sb(III) and $\mathrm{Sb}(\mathrm{V})$ Pattern. Soil and Sediment Contamination 23(1), 37-48.

38. Xiao G., Wang Y., Xu S., Li P., Yang C., Jin Y., Sun Q., Su H. 2019. Superior Adsorption Performance of Graphitic Carbon Nitride Nanosheets for Both Cationic and Anionic Heavy Metals from Wastewater. Chinese Journal of Chemical Engineering, 27(2), 305-13.

39. Zhang B., Fu Z., Wang J., Zhang L. 2019. Farmers' Adoption of Water-Saving Irrigation Technology Alleviates Water Scarcity in Metropolis Suburbs: A Case Study of Beijing, China. Agricultural Water Management, 212, 349-357. 